\title{
Single Instrument for Hemostatic Control in Laparoscopic Partial Nephrectomy in a Porcine Model Without Renal Vascular Clamping*
}

\author{
Jorge Subirá Ríos, M.D., Ph.D., José M. Sánchez Zalabardo, M.D., Ph.D.,' \\ Fernando Burdio, M.D., Ph.D., ${ }^{2}$ Enrique Berjano, Ph.D., ${ }^{3}$ Manuel Moros, Ph.D., ${ }^{4}$ Ana Gonzalez, Ph.D., 5 \\ Ana Navarro, M.D., Ph.D., ${ }^{6}$ and Antonio Güemes, M.D., Ph.D. ${ }^{6}$
}

\begin{abstract}
Purpose: To test the viability of a new device to obtain hemostasis during laparoscopic partial nephrectomy (LPN) without vascular clamping.

Materials and Methods: We performed a comparative experimental study between a new radiofrequency (RF)assisted device consisting of a handheld instrument that simultaneously conducts coagulation and cutting tasks without hilar clamping $v s$ a standard technique with hilar clamping. A porcine model was used (10 animals per group) with survival of 17 days.

Results: The estimated blood loss with the new device was significantly lower than with the standard technique $(15.5 \pm 23.7$ vs $79.4 \pm 76.3 \mathrm{~mL})$. Although transection time was longer with the new device $(10.7 \pm 13.7$ vs $2.1 \pm 1.2 \mathrm{~min}$ ), the total operative time was significantly shorter ( $35.3 \pm 13.7$ vs $60.2 \pm 10.5 \mathrm{~min})$. Evidence of localized urinary extravasation (urinoma) was identical in both groups (five cases). The group subjected to the new device, however, showed a significantly higher number of cases of leakage after conducting the methylene-blue test: eight $(80 \%)$ cases vs only one $(11 \%)$ with the standard technique. Necrosis depth was significantly greater with the new device $(6.6 \pm 0.9$ vs $<1 \mathrm{~mm})$.

Conclusions: The experimental results suggest that the proposed RF-assisted device provides adequate hemostatic control during transection of the renal parenchyma without additional instruments or surgical maneuvers and could therefore be a valuable adjunct for LPN without vascular clamping. The device was unsuccessful in effectively sealing the collecting system.
\end{abstract}

\section{Introduction}

$\mathbf{H}$ EMOSTASis is STILl a CHALLENGe during laparoscopic partial nephrectomy (LPN). Although partial temporary renal hilar clamping (both arteriovenous or arterial alone) provides a bloodless field, the longer warm ischemia time is associated with short- and long-term renal consequences. ${ }^{1}$ The laparoscopic approach thus becomes much more complex and morbidity increases, achieving similar results to the gold standard (open surgery) only after a long learning curve. The optimal surgical tool for performing pure LPN would allow for resection of lesions, control of arterial and venous bleeding without hilar clamping, clean removal of the tumor with a minimal margin, and provide closure or sealing of the collecting system. ${ }^{2}$ New technology that is capable of effective coagulation and dissection through perfused renal tissue would therefore be a valuable surgical adjunct. ${ }^{3}$

To date, different radiofrequency (RF)-assisted devices have been proposed to perform LPN without renal clamping. Some are based on the pioneer idea of Weber and associates ${ }^{4}$ of using RF needle electrodes to obtain a wide line of coagulated (avascular) tissue before dividing the line with a scalpel, thereby achieving bloodless resection. In this respect, some experimental ${ }^{5}$ and clinical $^{6}$ studies have conducted LPN using the Habib 4x Laparoscopic device (Angio Dynamics, Queensbury, NY), which had previously managed to reduce

\footnotetext{
${ }^{1}$ Department of Urology, Hospital Clínico Universitario Lozano Blesa, Zaragoza, Spain.

${ }^{2}$ Department of Surgery, Hospital del Mar, Barcelona, Spain.

${ }^{3}$ Biomedical Synergy, Electronic Engineering Department, Universidad Politécnica de Valencia, Valencia, Spain.

${ }^{4}$ Department of Pathology, Hospital Clínico Universitario Lozano Blesa, Zaragoza, Spain.

${ }^{5}$ Department of Animal Pathology and Surgery, Veterinary Faculty, University of Zaragoza, Zaragoza, Spain.

${ }^{6}$ Department of Surgery A, Hospital Clínico Universitario Lozano Blesa, Zaragoza, Spain.

Presented at the 28th World Congress of Endourology and SWL, September 1-4, 2010. Chicago, Illinois.

*A video demonstrating this new device is available at www.liebertonline.com/end
} 
blood loss in laparoscopic liver resections. Another experimental study used a bipolar needle electrode to create a regional coagulation zone before resection. ${ }^{7}$ These devices do not cut the tissue, a process that has to be conducted by cold scissors ${ }^{5,7}$ or other means, such as the Harmonic scalpel. ${ }^{8}$ In addition, the coagulation margin is not always perfect, and spot electrocautery may have to be used to control minor venous bleeding. ${ }^{7}$

Other hand-held RF-assisted devices do not merely create a coagulated margin before cutting, but are used for dissection and coagulation. Included in this group is the TissueLink Floating Ball (Tissuelink Medical, Dover, NH), which has a water-cooled monopolar electrode for blunt dissection and coagulation. This uses RF energy to seal small blood vessels and achieves good hemostasis before parenchymal resection. $\mathrm{RF}$ energy is transmitted by saline irrigation and converted into thermal energy on the target tissue. Scar formation is prevented by the saline, because the coagulated area remains cool and the temperature stays at or below $100^{\circ} \mathrm{C}$. This device had previously been used in LPN without clamping in experimental $^{2,9}$ and clinical ${ }^{10,11}$ studies.

Unfortunately, these saline-drip-based devices have serious drawbacks: (1) The risk of burning contiguous organs by the hot saline; (2) the cutting of tissue is impaired because of the instruments not being sharp; and (3) the saline flow rate is critical to producing the desired hemostatic effect without excessive charring. ${ }^{2}$

These problems, which also occur in hepatic resection, impelled us to design a new device based on a monopolar electrode that: (1) Uses RF energy to coagulate tissue; (2) includes an internal cooling system to achieve the advantages of the TissueLink device without the need to adjust flow rate or the risk of burning by hot saline; and (3) includes an attached sharp blade to accomplish resection. The preliminary results of the device in parenchyma division and hemostasis in liver resection without clamping, both in experimental open ${ }^{12}$ and laparoscopic ${ }^{13}$ studies, and a preliminary clinical study ${ }^{14}$ encouraged us to investigate its feasibility as a means of conducting LPN without vascular clamping.

The objective of this study was to test the viability of the proposed device to obtain hemostasis during LPN without vascular clamping. For this, we planned an experimental study to compare the new device with a standard technique using a porcine model with a survival of 17 days. A secondary objective was to test the performance of the device in sealing the collecting system.

\section{Materials and Methods}

\section{Description of the device}

The device, Coolinside ${ }^{\circledR}$ (Apeiron Medical, Valencia, Spain), consists of a handheld instrument that conducts two surgical tasks simultaneously: Coagulation and cutting (Fig. 1). Coagulation is performed by a metallic electrode $30 \mathrm{~cm}$ long and $2.8 \mathrm{~mm}$ in diameter that is connected to an RF generator CC-1 (Radionics, Burlington, MA) operating at maximum power (around $90 \mathrm{~W}$ ) in manual mode. The electrode is internally cooled with chilled saline $\left(0^{\circ} \mathrm{C}\right)$ by means of a peristaltic pump (Radionics, Burlington, MA) at a rate of approximately $130 \mathrm{~mL} / \mathrm{min}$ to keep its surface cool, avoiding carbonized tissue sticking to the electrode and impeding the flow of electrical current.

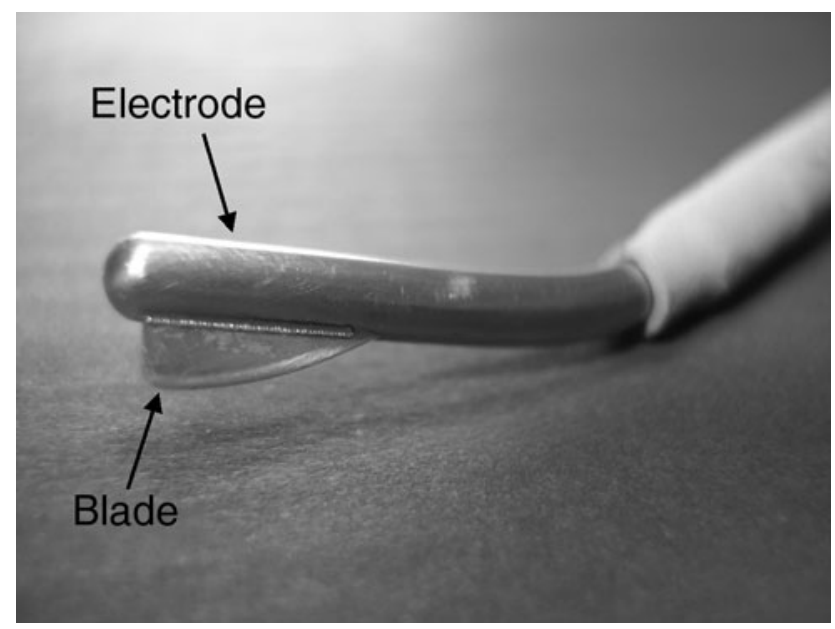

FIG. 1. The new radiofrequency (RF)-assisted device for laparoscopic partial nephrectomy (LPN). Photo shows the detail of the electrode with the sharp blade attached to the tip. Note the blunt bladeless side of the tip that allows coagulation of small vessels.

Cutting is accomplished by a sharp blade $6.3 \mathrm{~mm}$ long and $2.5 \mathrm{~mm}$ wide that is attached distally to the tip (Fig. 1). The electrode is at an angle of about 135 degrees to the handle to pass through the trocar. The main task of the device is to cut precoagulated tissue. ${ }^{15}$ Figure 2 shows cross-sectional views of a fragment of target tissue at different stages. Briefly, the surgeon moves the distal side of the device backward over the surface of the tissue to be transected. The proximal zone of the electrode coagulates the tissue with a backward movement and is subsequently transected by the blade that is located distally at the tip. The sharp blade only cuts the tissue that has previously been coagulated and thus keeps bleeding to a minimum.

\section{Animal model}

Twenty female Landrace pigs that weighed 31 to $42 \mathrm{~kg}$ were divided into two experimental groups for the comparative study. Ten animals from each group underwent LPN consisting of removal of the lower pole of the left kidney. In both groups, the animals were premedicated with tiletaminezolazepam $10 \mu \mathrm{g} / \mathrm{kg}$ intramuscularly, medetomidine $0.03 \mathrm{mg} /$ $\mathrm{kg}$ intravenously (IV), and atropine $0.04 \mathrm{mg} / \mathrm{kg}$ IV. Cefazolin $1 \mathrm{~g}$ IV was used as antibiotic prophylaxis. In the operating room, anesthesia was maintained with propofol $10 \mathrm{mg} / \mathrm{kg}$ IV with a continuous perfusion of fentanyl $0.08 \mathrm{mg} / \mathrm{h} \mathrm{IV}$ and fluid therapy.

\section{Surgical techniques}

All procedures were performed by a single surgeon (JMS). The optical trocar was placed using a Veress needle. Two trocars were placed under direct vision: One of $5 \mathrm{~mm}$ in the left hypochondrium and a $12 \mathrm{~mm}$ in the left flank. The left kidney was exposed after dissection of the parietal peritoneum, giving access to the lower pole. In both groups, the LPN involved a deep collecting system entry. In group 1, LPN was conducted using the proposed single RF-assisted device to obtain both transection and hemostasis. No attempt was 

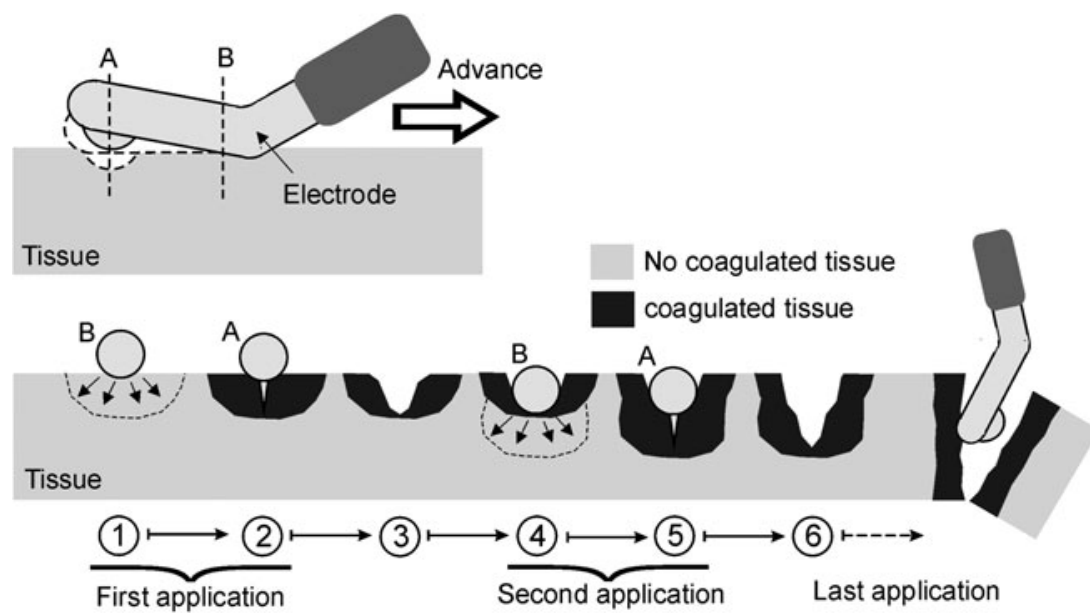

FIG. 2. Main role of the new RF-assisted device for bloodless resection. Top: Lateral view of the device shows the distal section (A) with the blade, the proximal section (B) joined to the insulated part (dark gray), and the advance direction of the device on the target tissue. Bottom: Cross-sectional views of a fragment of target tissue show two sequential applications. Each application consists of two steps: First, the tissue is heated (and coagulated) by applying radiofrequency currents (arrows) using the proximal section (steps 1 and 4), after which the blade of the distal section resects the previously coagulated tissue (steps 2 and 5). The electrode can be slightly tilted to ensure that initially only the proximal section is in contact with the tissue (solid lines). After this coagulation, the entire electrode can be used to cut the tissue surface (dashed lines). Finally, after removing the fragment, the last application performs preventive coagulation with the blunt tip on the remaining section surface. made to close the collecting system, control hemostasis, or use any other type of agent, such as fibrin glue. In fact, the effect of the device on the integrity of the collecting system was an important issue to be assessed in group 1. In this group, in all cases, LPN was conducted without hilum clamping or stitches and the device was inserted through the 12-mm trocar. Once the tissue fragment was removed, the blunt tip was used to conduct preventive coagulation of the remaining section surface.

In group 2, LPN was conducted with the technique usually used in our institution; ie, arterial hilum occlusion using a Rummel tourniquet as modified by Rosales, cutting with cold scissors, hemostatic sutures, and continuous suture for closing the collecting system and treatment of the resection site with sealant to prevent delayed urinary leaks (Surgicel ${ }^{\circledR}$, Ethicon). And finally, continuous suture for closing the renal parenchyma is conducted on the sealant.

In both groups, estimated blood loss $(\mathrm{mL})$ and transection and operative time (minutes) were assessed during the surgical procedure. The resected specimens were put into plastic bags and conserved for analysis. The postoperative analgesia consisted of ketorolac $30 \mathrm{mg} / 24 \mathrm{~h}$ using patches for the first postoperative day and subsequently as necessary. The weight (g) of the resected specimens was recorded. The transection zone was approximately ellipsoid, and the area was calculated by the ellipsoid formula $\pi \times a \times b, a$ and $b$ being the ellipsoid radii. This estimation allowed blood loss to be calculated per transection area $\left(\mathrm{mL} / \mathrm{cm}^{2}\right)$.

Survival studies are required to detect the incidence of postoperative bleeding and urinary fistula, because they are the most frequent complications that are encountered after LPN. ${ }^{16}$ The animals were therefore euthanized on the 17 th day, after which they underwent open nephrectomy with proximal ureter dissection. The kidney was explanted, and its length and weight were recorded. The appearance and integrity of the residual kidney on the side of the resection were observed, as was the incidence of bleeding and urinary leakage in both groups. Signs of coagulum, which would suggest late bleeding, were looked for. Possible urine leakage was determined by two methods: One by searching for urinary extravasation (urinomas) and in the other, the integrity of the collecting system was assessed by dividing the ureter and injecting it with methylene blue. ${ }^{2}$

\section{Histopathologic evaluation}

The histopathologic evaluation was performed by a single pathologist (MM). The gross and histopathologic evaluations were conducted on the cut edge of the resection of the remnant kidney once the animals were euthanized. The samples were processed with hematoxylin and eosin (H\&E) and Masson trichrome techniques. Necrosis depth $(\mathrm{mm})$ was considered as mean depth calculated by microscopic assessment (using findings from the different staining techniques) at five equidistant points in the remaining resection surface. Finally, in group 1 only, a viability study of the remaining kidney was conducted by analyzing renal cells at a distance from the transection zone by staining for oxidate pathway enzymes according to a modification of the Nottingham method using nicotinamide adenine dinucleotide (NADH). ${ }^{17}$

\section{Statistical analysis}

Numerical variables were compared between groups using the Student or $U$ Mann-Whitney test, and categorical variables were compared using the Fisher exact test. The Kolmogorov-Smirnov test was used to check the normality of the data distribution. Data are displayed as the mean \pm standard deviation. The significance level was 0.05. Data collection and analyses were performed with SPSS 15.0 statistical software (SPSS, Chicago, IL).

\section{Results}

LPN was successful in all the group 1 cases without the need for hilar clamping. The video shows part of the surgical procedure using the new device. In contrast, in group 2, one fatal event occurred during dissection of the renal hilum when the renal artery was unintentionally damaged and the bleeding could not be controlled. The experiment finished with nephrectomy, and the animal was sacrificed. The bleeding associated with this event was not included in the estimated blood loss in group 2. The rest of the animals (10 in 
group 1 and 9 in group 2) survived for 17 days with no complications. In all these cases, the transection involved a considerable aperture in the collecting system, as can be macroscopically observed in Figure 3. The preventive coagulation of the remaining section surface in all group 1 cases just after transection took $46.1 \pm 30.4$ seconds. No bleeding was observed in any case. Table 1 shows the operative outcomes in both groups. The estimated blood loss using the new device was $15.5 \pm 23.7 \mathrm{~mL}$, which was significantly lower than with the standard technique $(79.4 \pm 76.3 \mathrm{~mL})$. The blood loss per transection area was also significantly lower with the new device $\left(2.3 \pm 3.0 \mathrm{~mL} / \mathrm{cm}^{2}\right)$ than the standard technique $\left(11.8 \pm 11.1 \mathrm{~mL} / \mathrm{cm}^{2}\right)$.

The group 1 transections took $10.7 \pm 13.7$ minutes, while in group 2 , this time was significantly shorter $(2.1 \pm 1.2 \mathrm{~min})$. For total time of the surgical procedure-ie, including the time necessary to prepare and clamp the renal hilum (group 2)the new device was significantly faster $(35.3 \pm 13.7 \mathrm{~min})$ than the standard technique $(60.2 \pm 10.5 \mathrm{~min})$. Mean clamping time for the renal artery (warm ischemia time) in group 2 was $36.1 \pm 7.7$ minutes.

Figure 4 shows the resected specimens of both groups There were no significant differences between groups: $17.1 \pm 6.1 \mathrm{~g}$ in group 1 and $12.3 \pm 5.5 \mathrm{~g}$ in group 2 . The specimens were significantly longer in group $1(37 \pm 8 \mathrm{~mm}$ vs $27 \pm 10 \mathrm{~mm}, P=0.033$ ), which was probably because these animals were slightly larger than those in group 2 $(38.2 \pm 0.8 \mathrm{~kg}$ vs $34.7 \pm 0.9 \mathrm{~kg})$. Table 2 shows the comparative outcomes after euthanization. Renal weight was $99.4 \pm 21.5 \mathrm{~g}$ in group 1 and $78.7 \pm 14.5 \mathrm{~g}$ in group 2 . No cases of postoperative bleeding were found in group 1 . In contrast, two cases of coagulum were found in group 2. Adhesion of the bowels to the remaining transected zone were found in all the cases and was especially intense in six animals in group 1 and five in group 2, but had no postoperative clinical impact in any case. Evidence of localized urinary extravasation (urinoma) was identical in both groups (five in each). Group 1, however, showed a significantly higher number of leakage cases in the methylene-blue test: eight $(80 \%)$ cases vs only $1(11 \%)$ in group 2 .

Histologic analysis in group 2 showed earlier hemorrhage and formation of vascular-fibrous tissue with scar-type in-

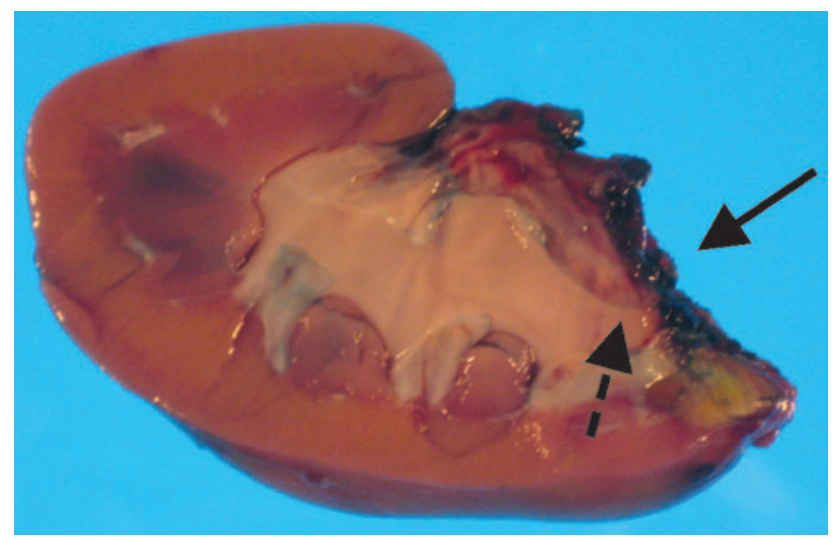

FIG. 3. Remaining kidney explanted immediately after necropsy in group 1. Solid arrow indicates the transection zone, and dashed arrow shows the opening of the urine collecting system. flammatory infiltration extended toward contiguous parenchyma. Within this tissue, the suture points were enclosed by chronic inflammatory reaction with multinuclear macrophages. The chronic alterations in group 1 were characterized by a zone of tissue with coagulative necrosis. Between necrotic parenchyma and viable renal tissue, we found a zone with undefined margins that was characterized by proliferation of vessels and mononuclear-type infiltration. The study with NADH in group 1 demonstrated the total loss of enzymatic activity in necrotic zones and viability of renal tissue at a distance from the section zone. Necrosis was significantly deeper in group $1(6.6 \pm 0.9 \mathrm{~mm})$ than in group 2 , in which it was less than $1 \mathrm{~mm}$ in all cases.

\section{Discussion}

The main objective of the study was to test the viability of the proposed device to obtain hemostasis during LPN without vascular clamping. This was done by comparing its performance with a standard technique on a porcine model with survival of 17 days. In general, the proposed device produced sufficient coagulation of the renal parenchyma to achieve a nearly bloodless cut with the blade. It was also proficient in the hemostatic control of large vessels (up to $3 \mathrm{~mm}$ ) when using the blunt tip on the bleeding point, not only in the renal parenchyma, but also adjacent to the renal hilum. This was clearly observed in the fifth case in group 1 , where bleeding occurred in one superior arterial branch on commencing transection of the parenchyma next to the vascular hilum; bleeding was stemmed by use of the blunt electrode tip. Neither hilum lesion nor ischemic alteration of the remaining kidney was observed in this case during necropsy.

The capacity of the proposed device for achieving better hemostatic control during transection than the standard technique was clearly associated with the large difference in blood loss between groups, which was only $15.5 \pm 23.7 \mathrm{~mL}$ with the new device compared with $79.4 \pm 76.3 \mathrm{~mL}$ with the standard technique. This value was also considerably lower than those found in previous experimental LPN studies without vascular clamping using RF-assisted devices, such as $48 \pm 11 \mathrm{~mL}$ using a bipolar needle electrode, ${ }^{7} 45 \mathrm{~mL}$ with the Habib $4 \mathrm{x}^{5}$ or $49 \mathrm{~mL}$ using the TissueLink. ${ }^{2}$ Estimated blood loss values in clinical LPN cases without clamping with an RFassisted device are even higher, with values from $100 \mathrm{~mL}$ with the Habib $4 \mathrm{x}^{6}$ to a range between 100 and $350 \mathrm{~mL}^{10,11,18}$ with the TissueLink.

The low blood loss found in group 1 is probably closely related to the late hemorrhage risk. In this respect, the lack of postoperative bleeding in group 1 (assessed by the finding of coagulum during necropsy) suggests that the new device is capable of avoiding late bleeding, whereas coagulum was found in two cases in group 2. It should also be pointed out that after resection in group 1, the device was used to coagulate the surface of the remaining zone to prevent late bleeding. This preventive maneuver was similar to that conducted by Ong and coworkers ${ }^{7}$ with spots of monopolar electrocoagulation to complete the desiccation and cauterization of the remaining renal parenchyma. Because the proposed device is capable of creating very deep lesions (see below), however, this preventive coagulation is probably more efficient than conventional electrocautery. 
Table 1. Operative Outcomes in the Two Experimental Groups (Mean \pm Standard Deviation)

\begin{tabular}{|c|c|c|c|}
\hline & $\begin{array}{c}\text { Group } 1(\mathrm{n}=10) \\
\text { New device }\end{array}$ & $\begin{array}{l}\text { Group } 2(\mathrm{n}=10) \\
\text { Standard technique }\end{array}$ & $\mathrm{P}$ \\
\hline Estimated blood loss (mL) & $15.5 \pm 23.7$ & $79.4 \pm 76.3$ & 0.038 \\
\hline Operative time (min) & $35.3 \pm 13.7$ & $60.2 \pm 10.5$ & $<0.001$ \\
\hline Transection time (min) & $10.7 \pm 13.7$ & $2.1 \pm 1.2$ & 0.001 \\
\hline Resected specimen weight (g) & $17.1 \pm 6.1$ & $12.3 \pm 5.5$ & n.s. \\
\hline Resected specimen length (mm) & $37 \pm 8$ & $27 \pm 10$ & 0.033 \\
\hline Transection area $\left(\mathrm{cm}^{2}\right)$ & $6.7 \pm 1.8$ & $6.5 \pm 1.2^{\mathrm{a}}$ & n.s. \\
\hline Blood loss per transection area $\left(\mathrm{mL} / \mathrm{cm}^{2}\right)$ & $2.3 \pm 3.0$ & $11.8 \pm 11.1^{\mathrm{a}}$ & 0.034 \\
\hline
\end{tabular}

${ }^{a}$ These data were obtained after necropsy on the 17th day, and hence only nine animals were considered in group 2. n.s. $=$ not significant.

On this point, the results of this study suggest that the new device is also proficient in the hemostatic control of vessels up to $3 \mathrm{~mm}$ by using the blunt tip on the bleeding point. Although other handheld RF-assisted devices, such as TissueLink, are able to stem bleeding of 1 to $2 \mathrm{~mm}$ vessels ${ }^{2}$ and even $3 \mathrm{~mm},{ }^{19}$ the process is more time-consuming than vessel precoagulation. $^{2}$ In addition, TissueLink is not usually able to control large bleeding points, such as openings in the trunks of the hepatic vein, ${ }^{21}$ which the new device has proved it can do. ${ }^{14}$

One of the most notable results in our study was the dramatic difference in the operative and transection times of the two groups. While the new device needed more time to complete transection than the standard technique $(10.7 \pm 13.7$ vs $2.1 \pm 1.2 \mathrm{~min})$, its total operative time was significantly shorter ( $35.3 \pm 13.7$ vs $60.2 \pm 10.5 \mathrm{~min})$. The standard technique needed longer operative time, because it included other tasks, such as hilum dissection, arterial clamping, cutting the parenchyma, hemostatic control, closure of the collecting system, and parenchyma suturing. In fact, with the standard technique, the transection time is the easiest phase of the procedure (cold cut); however, this is only true if clamping is effective. In fact, in one case in group 2, we had surgical problems with the Rummel tourniquet, which lengthened the transection time because of bleeding. This impaired visibility and called for replacement of vascular clamping. All in all, our findings suggest that the new device could reduce the overall complexity of the technique and the number of possible complications and hence achieve a more reproducible procedure than the standard technique.

It is important to compare the group 1 results with previous experimental studies without vascular clamping. In this respect, Ong and colleaues ${ }^{7}$ reported a mean operative time of 29 minutes, which, although it is lightly shorter than ours
( $35.3 \mathrm{~min}$ ), this value corresponded to $80 \%$ of the animals (10/ 12) because of two cases that needed temporary renal arterial occlusion to aid in hemostasis. In our study, renal arterial clamping was not needed in any of the cases.

Other experimental studies with RF-assisted devices reported mean operative times longer than those obtained in the present study, from 57 minutes $^{5}$ with the Habib $4 x$ to 148 minutes with the TissueLink. ${ }^{2}$ Even when using other energy sources for LPN without clamping, such as laser, the mean operative time is still longer, ranging from 35 to 60 minutes. ${ }^{21}$ These operative times are for LPN without clamping in animal models and therefore cannot be compared with clinical cases, in which the values are about 150 to 175 minutes. ${ }^{6,11}$

Considering the previous results of the failure of RF application to conserve the integrity of the collecting system, ${ }^{2}$ our hypothesis never explicitly included sealing the collecting system to control urinary leakage, so that the preventive coagulation conducted on the surface of the remaining zone in group 1 was actually aimed at achieving hemostasis. We did not find any relation between coagulation time and the incidence of leakage and urinoma; ie, we cannot determine whether preventive coagulation protects against or actually causes leakage. Even more, because no bleeding was found in the remaining zone just after the resection, it may be totally unnecessary.

An equal number of urinomas was found in both groups. The leakage test based on methylene blue, however, was positive in $80 \%$ of the cases in group 1 and only $11 \%$ in group 2 . This test is experimentally used to check the potential leak by using some stain, such as methylene blue, ${ }^{2}$ indigo carmine, ${ }^{21,22}$ or even simply saline. ${ }^{23}$ In fact, in clinical cases where a broad opening of the collecting system has been conducted, this method has been proposed to intraoperatively locate the leakage point and check the total sealed after repair. ${ }^{24}$
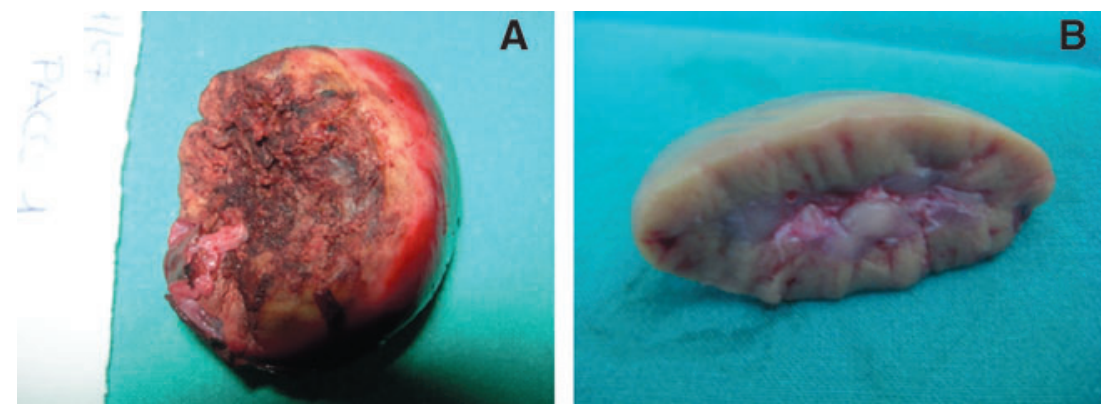

FIG. 4. Resected specimens of groups 1 (A) and 2 (B) just after LPN. Note the opening of the collecting system. 
Table 2. Outcomes of the Two Experimental Groups After Euthanization (Mean \pm Standard Deviation)

\begin{tabular}{lccc}
\hline & $\begin{array}{c}\text { Group 1 } \\
(n=10) \\
\text { New device }\end{array}$ & $\begin{array}{c}\text { Group 2 } \\
(n=9)\end{array}$ & $\begin{array}{c}\text { Standard } \\
\text { technique }\end{array}$ \\
\hline $\begin{array}{c}\text { Necrosis depth (mm) } \\
\text { Urine leakage } \\
\text { (methylene-blue test) }\end{array}$ & $\begin{array}{c}6.6 \pm 0.9 \\
8 / 10\end{array}$ & $1 / 9$ & 0.005 \\
$\begin{array}{c}\text { Urinary extravasation } \\
\text { (urinoma) }\end{array}$ & $5 / 10$ & $5 / 9$ & n.s. \\
$\begin{array}{c}\text { Postoperative bleeding } \\
\text { (coagulum) }\end{array}$ & $0 / 10$ & $2 / 9$ & n.s. \\
$\begin{array}{c}\text { Tissue viability } \\
\text { (NADH test) }\end{array}$ & $10 / 10$ & $9 / 9$ & n.s. \\
\hline
\end{tabular}

$\mathrm{NADH}=$ nicotinamide adenine dinucleotide

The low incidence of positive leakage results in group 2 can be explained as follows: There was an initial leak in five cases (formation of urinoma), and the urinary collecting system was later sealed in all cases except one. The situation was totally different in group 1, where the high leakage incidence suggests the new device is not able to successfully seal the collecting system. This would agree with the findings of experimental LPN using RF-assisted devices in which deep collecting system entry was made and no attempt was made to seal the system by agents such as fibrin glue. For instance, Sprunger and Herrell ${ }^{2}$ concluded that the TissueLink device does not provide any sealing of the collecting system, because urinomas were observed in all cases, and retrograde perfusion with methylene blue demonstrated gross extravasation from the resected surface.

Future experimental studies should therefore be planned to assess the combined effect of the new device along with the use of sutures and sealing agents at the resection site. In clinical practice, however, it is not usual to make a broad opening in the collecting system, as was done in this study and, in fact, the best way to close such an opening is by suture.

Histologic analysis of the remaining transection zone (after necropsy) showed that the new device produces significantly deeper coagulative necrosis than the standard technique $(6.6 \pm 0.9 \mathrm{~mm} v \mathrm{~s}<1 \mathrm{~mm})$; ie, the necrosis margin created by the new device is significantly thicker than that produced by suturing the renal parenchyma. This depth was similar to that created with TissueLink (approximately 6 to $8 \mathrm{~mm})^{2}$ in a perfused kidney model, and less than that created in the same model with needle-type RF-assisted devices $(2-4 \mathrm{~mm}), 5,7$ or with other energy sources, such as laser $(2-6 \mathrm{~mm})^{21}$ and Harmonic scalpel $(4 \mathrm{~mm}){ }^{9}$

Both TissueLink and the new device eliminate healthy parenchyma, which could be an important factor, for example, in cases of multiple bilateral tumors, where it is crucial to preserve as much healthy tissue as possible. In spite of this limitation, the new device does give adequate control of bleeding during LPN without vascular clamping. The design is based on an internal cooling circuit that avoids the risk of burns from hot saline and the critical point of adjusting saline flow rate to achieve the desired hemostatic effect, as opposed to the TissueLink. In addition, the cutting edge allows easy resection of the tissue.

\section{Limitations of the study}

The main limitation of this study is that neither tumor nor human tissue was involved. There were also significant differences between the groups regarding animal weights. Because those in group 1 were bigger, the kidneys also were bigger (the excised poles were significantly longer in group 1). In terms of length, this meant that $24 \%$ of the kidney was cut in group 1, as compared with $19 \%$ in group 2, which implies that the proposed device had to conduct LPN on larger organs, which were therefore more perfused with larger vessels and needed broader opening of the collecting system. Another limitation related to the pig model for partial nephrectomy is the irrigation pattern in this model, which does not exactly represent that of the human kidney.

\section{Conclusions}

The experimental results in a pig model suggest that the proposed RF-assisted device provides adequate hemostatic control during transection of the renal parenchyma without any additional instruments or surgical maneuvers, and therefore could be a valuable adjunct for LPN without vascular clamping. In addition, it could also significantly reduce the complexity of the technique by needing a shorter operative time, reducing intraoperative morbidity, and in turn achieving a reproducible method more appropriate for the laparoscopic approach. In turn, this could lead to shortening the learning curve of this technique. Unfortunately, the device was unsuccessful in effectively sealing the collecting system, which means that sutures and sealing agents should be combined with the new device in cases that involve deep collecting system entry.

\section{Acknowledgments}

This work received financial support from the Spanish "Plan Nacional de I+D+I del Ministerio de Ciencia e Innovación," Grant No. TEC2008-01369/TEC. The translation of this paper was funded by the Universidad Politécnica de Valencia, Valencia, Spain.

\section{Disclosure Statement}

Drs. Burdio and Berjano declare an interest (stockholder) in Apeiron Medical, a company that has a license for the patent application US 2010/137856 A1, on which the device tested in this study is based. The other authors have no competing interests.

\section{References}

1. Thompson RH, Lane BR, Lohse CM, et al. Every minute counts when the renal hilum is clamped during partial nephrectomy. Eur Urol 2010;58:340-345.

2. Sprunger J, Herrell SD. Partial laparoscopic nephrectomy using monopolar saline-coupled radiofrequency device: Animal model and tissue effect characterization. J Endourol 2005;19:513-519.

3. Herrell SD, Levin BM. Laparoscopic partial nephrectomy: Use of the TissueLink hemostatic dissection device. J Endourol 2005;19:446-450.

4. Weber JC, Navarra G, Jiao LR, et al. New technique for liver resection using heat coagulative necrosis. Ann Surg 2002;236: 560-563. 
5. Zeltser IS, Gupta A, Bensalah K, et al. Focal radiofrequency coagulation-assisted laparoscopic partial nephrectomy: A novel nonischemic technique. J Endourol 2008;22:1269-1273.

6. Andonian S, Adebayo A, Okeke Z, et al. Habib laparoscopic bipolar radiofrequency device: A novel way of creating an avascular resection margin in laparoscopic partial nephrectomy. J Laparoendosc Adv Surg Tech A 2008;18:853-856.

7. Ong AM, Bhayani SB, Hsu TH, et al. Bipolar needle electrocautery for laparoscopic partial nephrectomy without renal vascular occlusion in a porcine model. Urology 2003;62: 1144-1148.

8. Jackman SV, Cadeddu JA, Chen RN, et al. Utility of the harmonic scalpel for laparoscopic partial nephrectomy. J Endourol 1998;12:441-444.

9. Coleman J, Singh A, Pinto P, et al. Radiofrequency-assisted laparoscopic partial nephrectomy: Clinical and histologic results. J Endourol 2007;21:600-605.

10. Sundaram CP, Rehman J, Venkatesh R, et al. Hemostatic laparoscopic partial nephrectomy assisted by a watercooled, high-density, monopolar device without renal vascular control. Urology 2003;61:906-909.

11. Tan YH, Young MD, L'Esperance JO, et al. Hand-assisted laparoscopic partial nephrectomy without hilar vascular clamping using a saline-cooled, high-density monopolar radiofrequency device. J Endourol 2004;18:883-887.

12. Burdío F, Navarro A, Berjano E, et al. A radiofrequencyassisted device for bloodless rapid transection of the liver: A comparative study in a pig liver model. Eur J Surg Oncol 2008;34:599-605.

13. Navarro A, Burdio F, Berjano EJ, et al. Laparoscopic bloodsaving liver resection using a new radiofrequency-assisted device: preliminary report of an in vivo study with pig liver. Surg Endosc 2008;22:1384-1391.

14. Burdío F, Grande L, Berjano E, et al. A new single-instrument technique for parenchyma division and hemostasis in liver resection: A clinical feasibility study. Am J Surg 2010; 200:e75-e80.

15. Burdío F, Berjano EJ, Navarro A, et al. Research and development of a new RF-assisted device for bloodless rapid transection of the liver: Computational modeling and in vivo experiments. Biomed Eng Online 2009;8:6.

16. Porpiglia F, Volpe A, Billia M, Scarpa RM. Laparoscopic versus open partial nephrectomy: Analysis of the current literature. Eur Urol 2008;53:732-743.
17. Topp SA, McClurken M, Lipson D, et al. Saline-linked surface radiofrequency ablation: Factors affecting steam popping and depth of injury in the pig liver. Ann Surg 2004; 239:518-527.

18. Urena R, Mendez F, Woods M, et al. Laparoscopic partial nephrectomy of solid renal masses without hilar clamping using a monopolar radio frequency device. J Urol 2004;171: 1054-1056.

19. Rubinstein M, Moinzadeh A, Colombo JR Jr, et al. Energy sources for laparoscopic partial nephrectomy-critical appraisal. Int Braz J Urol 2007;33:3-10.

20. Poon RT. Current techniques of liver transection. HBP (Oxford) 2007 ; 9:166-173.

21. Bui MH, Breda A, Gui D, et al. Less smoke and minimal tissue carbonization using a thulium laser for laparoscopic partial nephrectomy without hilar clamping in a porcine model. J Endourol 2007;21:1107-1111.

22. Terai A, Ito N, Yoshimura $\mathrm{K}$, et al. Laparoscopic partial nephrectomy using microwave tissue coagulator for small renal tumors: Usefulness and complications. Eur Urol 2004;45:744-748.

23. Corvin S, Oberneder R, Adam C, et al. Use of hydro-jet cutting for laparoscopic partial nephrectomy in a porcine model. Urology 2001;58:1070-1073.

24. Desai MM, Gill IS, Kaouk JH, et al. Laparoscopic partial nephrectomy with suture repair of the pelvicaliceal system. Urology 2003;61:99-104.

Address correspondence to:

Jorge Subira Rios, M.D., Ph.D. Department of Urology

Hospital Clinico Universitario Lozano Blesa

Plaza San Francisco 7, 3D

Zaragoza, 50006

Spain

E-mail: kokedoc@hotmail.com

$\begin{aligned} & \text { Abbreviations Used } \\ \mathrm{IV}= & \text { intravenously } \\ \mathrm{LPN}= & \text { laparoscopic partial nephrectomy } \\ \mathrm{NADH}= & \text { nicotinamide adenine dinucleotide } \\ \mathrm{RF}= & \text { radiofrequency }\end{aligned}$


